\title{
The relation of mortality in England and Wales 1969-73 to measurements of air pollution
}

\author{
S. CHINN, C. du V. FLOREY, I. G. BALDWIN, AND M. GORGOL \\ From the Department of Community Medicine, St. Thomas's Hospital Medical School, London
}

SUMmaRY The relation between mortality of people aged 45 to 74 and atmospheric smoke and sulphur dioxide in the county and London boroughs of England and Wales was investigated using data for the years 1969 to 1973 . Weighted multiple regression analyses, which took into account a number of socioeconomic and climatic variables, showed no consistent relation of smoke or sulphur dioxide with mortality from all causes or with mortality from specified causes postulated a priori to be related to pollution. In particular there was no significant association between smoke and mortality rates for respiratory illness. Comparison with results from similar analyses of data for the two previous decades suggested that a decline in the strength of associations had occurred in parallel with declining levels of the pollutants.

In the last 25 years a large number of studies have been published about the relation between outside air pollution and mortality, ${ }^{1-5}$ all of which have suggested that some portion of mortality -particularly that due to diseases of the respiratory tract-is associated with pollution.

Three studies of mortality in England and Wales have been reported for periods around the census years of 1951 and 1961.6 All three used county boroughs as the areas for which census and mortality data were obtained. Daly ${ }^{8}$ found that mortality from bronchitis was significantly related to indices of both domestic and industrial pollution, based on consumption, after allowing for differences in four social factors. Stocks ${ }^{7}$ found that bronchitis and lung cancer mortality were significantly related to deposited matter and smoke levels, taking only social class and population density into account. Gardner et $a l^{8}{ }^{8}$ found that mortality from bronchitis and cancer of the lung were associated with the 1951 index of domestic pollution, Daly's index. Their findings were for mortality centred around 1951 and 1961, and took nine socioeconomic factors into account in an index derived by principal components analysis.

Our study is a continuation of these earlier ones. We have used data centred about 1971 for all variables, including smoke and sulphur dioxide $\left(\mathrm{SO}_{2}\right)$ and we have included Daly's index as a measure of pollution 20 years before death.

\section{Materials and methods}

Data were obtained for the 116 county and London boroughs of England and Wales, which varied in population from 33176 to 1014670 , with a maximum area of $184 \mathrm{~km}^{2}$. Mortality rates, calculated by dividing the average annual number of deaths for 1969 to 1973 by the 1971 population, were obtained for age groups 45-54, 55-64, and 65-74. Data for infants under the age of 1 were also obtained, because of the finding by Collins $e t \mathrm{al}^{10}$ that mortality in this age group was related to pollution in data from 1958 to 1964 . All the causes of death used in the earlier British studies, and those used in an American study, ${ }^{11}$ were considered, but a number were omitted from analysis because of very small numbers of deaths or small variation between areas in the mortality rates. Full details can be found in a separate document.* In this paper results are reported for those causes of death for which there were a priori reasons for expecting a relation between pollution levels and mortality rates, namely all causes, malignant neoplasms of the stomach and of the trachea, bronchus and lung, influenza, pneumonia and chronic bronchitis. In addition we have included hypertensive disease and ischaemic heart disease for comparison with previous work. 'Bronchitis, emphysema and asthma' was omitted because the majority of deaths in this category overlap with those due to chronic bronchitis. For infants under the age of 1 only mortality data from all causes and pneumonia were analysed as these were the only rubrics with sufficient deaths.

Smoke and $\mathrm{SO}_{2}$ values were supplied by the Department of Industry's Warren Spring Laboratory. The data were obtained from the

*Full report submitted to the Department of the Environment, available from the authors on microfiche. 
National Survey of Smoke and Sulphur Dioxide. ${ }^{12}$ Distributions of data from individual sites over a year were positively skewed and approximately log-normal. For the majority of boroughs data for more than one site were available. There were in total 411 sites in 104 boroughs; 12 boroughs had to be omitted for lack of pollution data. The geometric means for the individual sites within a borough were averaged, and the median of the individual 90th centiles calculated. The corresponding means and 90th centiles were highly correlated $(r \sim 0.95)$, as were corresponding winter and annual figures, since pollution levels in the summer months were uniformly low. Winter mean levels of smoke and $\mathrm{SO}_{2}$ were therefore used in the analysis. Within the period 1969 to 1973 the year when the maximum number of boroughs had pollution levels available was 1971, and as levels for 1969 and 1971 were well correlated we chose to use the 1971 data.

The nine socioeconomic variables used by Gardner ${ }^{89}$ were derived from a number of sources relating to various years. The present study used data from the 1971 census to derive similar variables where possible. The variables used are shown in Table 1. After some investigation it was decided to use the variables individually, as the first principal component derived from all the socioeconomic variables with the exception of those relating to social class explained less of the variation in mortality, and this loss was not compensated for by the increase in degrees of freedom for estimating the residual variance.

Table 1 also shows the other variables that were taken into account. Temperature, latitude, and rainfall were used by Gardner, ${ }^{89}$ the latter two showing a number of significant associations with mortality, and temperature and humidity have been

Table 1 Confounding variables taken into account in the analysis

\footnotetext{
SOCIOECONOMIC VARIABLES (197I CENSUS)

Social class (proportions of adult males in each class and those not classified)

Population density (persons per hectare)

\% households with more than 1.5 persons/room

\% unemployed men

\% homes with no car

\% homes with two or more cars

\% population with A levels or higher qualification

\% homes owner-occupied

\% residents born outside UK

\% population aged under 15
}

\section{OTHER VARIABLES}

Latitude (ordnance survey grid reference)

Temperature (1971 mean minimum)

Rainfall (total 1971)

Water hardness (total)

\% population smoking by sex (General Household Survey: nine standard regions of England and Wales) found to be associated with mortality or morbidity in several studies. ${ }^{1314}$ Values of total water hardness were supplied by the Water Research Centre; these were used only in the analyses of mortality rates for hypertension and ischaemic heart disease. Daly ${ }^{8}$ included some data on smoking obtained by a market research organisation, but owing to the small numbers of people surveyed he found it necessary to combine county boroughs into eight groups. We investigated a number of possible sources of data on cigarette or tobacco consumption, but found none that could supply figures for the boroughs. Numbers of people participating in the General Household Survey were too small for division by borough, but proportions of male and female smokers were obtained for the nine standard regions of England and Wales.

The amount of variation between boroughs in the mortality rates that could be explained by sampling variation alone was calculated as described by Gardner. ${ }^{9}$ Gardner used the overall mortality rate for ages 45 to 64 . As the rates for the two groups 45 to 54 and 55 to 64 were markedly different, the overall rate was affected by the ratio of the populations in the two groups; for males this varied from 0.79 to 1.33 . We therefore used the average of the rates for the two age groups. Weighted multiple regressions of the logistic transformation of the mortality rates on the independent variables were carried out for the 95 county and London boroughs for which all data were available, and also for the 70 county boroughs alone. City and Temple, an outlier on mortality data as well as population, was among the London boroughs omitted because of missing data. The binomial weight commonly used for the analysis of proportions ${ }^{15}$ would take into account the different sizes of the boroughs. However, Pocock, Cook, and Beresford (unpublished observations) have shown that this weight is inappropriate when the residual variation about the fitted model is greater than the expected binomial sampling variation. If the sampling variation is a very small proportion of the residual variation an unweighted analysis can legitimately be used, but when the proportion is not insignificant, as was the case in our analyses, it is appropriate to use the optimal weighting defined by Pocock. This weight is the reciprocal of the sum of two components, one the binomial sampling variance, the other the estimate of the unexplained variance.

For 64 of the 104 boroughs in our data set, values of Daly's index were available. ${ }^{6}$ For these boroughs we carried out an unweighted regression of untransformed mortality rates in order to compare our results with those of Gardner and to attempt to assess the long-term effects of pollution. The causes 
of death analysed were as close in definition to those used by Gardner within the constraints of the changes in the International Classification of Diseases.

\section{Results}

The 1971 winter mean smoke and $\mathrm{SO}_{2}$ levels are shown in the Figure. The levels of smoke ranged from $15.0 \mu \mathrm{g} / \mathrm{m}^{3}$ in Torbay to $225 \mu \mathrm{g} / \mathrm{m}^{3}$ in Wigan; the higher values were all for county boroughs. In contrast, the $\mathrm{SO}_{2}$ levels ranged from $24.0 \mu \mathrm{g} / \mathrm{m}^{3}$ in Torbay to $317 \mu \mathrm{g} / \mathrm{m}^{3}$ in Tower Hamlets; the higher values, with the exception of that in Burton upon Trent, were in the London boroughs. The correlation between the two pollutants was low, $\mathbf{0 . 2 5}$ for the 95 county and London boroughs. Levels of smoke showed significant positive simple correlations with mortality rates for most causes of death at all ages. In general, levels of $\mathrm{SO}_{2}$ were less strongly associated with mortality.

The amount of variation in the mortality rates explained by sampling variation alone was a little greater than the $3.6 \%$ found by Gardner ${ }^{9}$ for

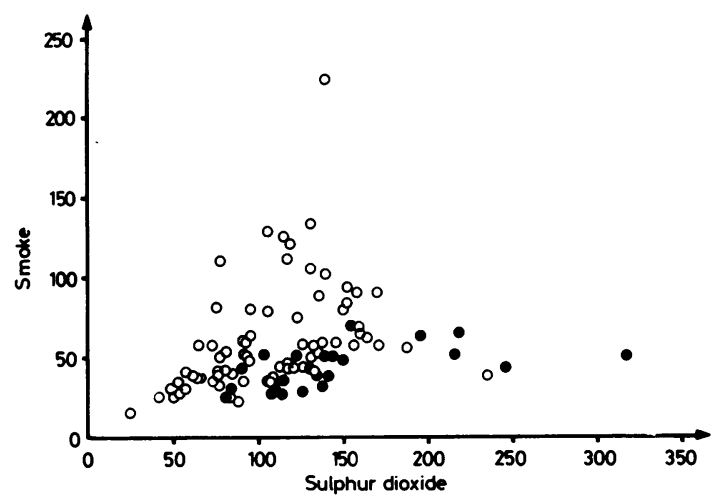

Figure The levels of smoke and sulphur dioxide in micrograms per cubic metre for the 70 county boroughs (O) and 25 London boroughs $(\mathrm{O})$ in the main analysis.

all-causes mortality in males aged 45 to 64 , being $9 \%$ for males aged 45 to 54 , and $6 \%$ for males aged 55 to 64. It was somewhat greater in females and larger for all-cause-specific mortality rates, but for all rubrics chosen the variation explained was less than $50 \%$ in at least one age group.

Table 2 Standardised regression coefficients $\dagger$ for smoke and sulphur dioxide measured in 1971 in 95 county and London boroughs according to cause of death, sex, and age

\begin{tabular}{|c|c|c|c|c|c|c|c|c|}
\hline \multirow[b]{3}{*}{ Cause of death } & \multicolumn{4}{|c|}{$M A L E S$} & \multicolumn{4}{|c|}{ FEMALES } \\
\hline & \multicolumn{2}{|l|}{$45-64$} & \multicolumn{2}{|l|}{$65-74$} & \multicolumn{2}{|l|}{$45-64$} & \multicolumn{2}{|l|}{$65-74$} \\
\hline & Smoke & $\mathrm{SO}_{2}$ & Smoke & $\mathrm{SO}_{2}$ & Smoke & $\mathrm{SO}_{2}$ & Smoke & $\mathrm{SO}_{2}$ \\
\hline All causes & -0.02 & 0.07 & -0.02 & 0.09 & 0.04 & 0.05 & 0.03 & $0 \cdot 12$ \\
\hline \multicolumn{9}{|l|}{ Malignant neoplasms } \\
\hline Stomach & 0.01 & -0.06 & 0.01 & 0.05 & $0 \cdot 10$ & 0.03 & -0.01 & -0.01 \\
\hline Trachea, bronchus, and lung & -0.03 & -0.00 & 0.02 & 0.06 & -0.04 & $0 \cdot 13$ & 0.04 & 0.01 \\
\hline Hypertensive disease & -0.06 & $0.35^{* *}$ & $-0 \cdot 10$ & 0.19 & -0.00 & $0 \cdot 16$ & 0.06 & 0.05 \\
\hline Ischaemic heart disease & 0.00 & 0.11 & 0.08 & $0 \cdot 06$ & -0.02 & 0.08 & 0.11 & 0.02 \\
\hline Influenza & -0.17 & $-0 \cdot 16$ & N $A^{* * *}$ & N A & N A & $\mathbf{N ~ A}$ & $\mathbf{N A}$ & $\mathbf{N A}$ \\
\hline Pneumonia & 0.11 & -0.15 & 0.04 & 0.03 & 0.08 & -0.06 & 0.10 & $0 \cdot 11$ \\
\hline Chronic bronchitis & -0.04 & 0.07 & 0.01 & $0.22 *$ & -0.01 & $0 \cdot 23^{* *}$ & 0.04 & $0 \cdot 11$ \\
\hline
\end{tabular}

+Increase, in standard deviation units, of dependent variable for one standard deviation increase in independent variable. Optimally weighted regression of logits of mortality rates.

*p $<0.10 \quad * *$ * $\quad * 0.05$ A $=$ not analysed

Table 3 Standardised regression coefficients $\dagger$ for smoke and sulphur dioxide measured in 1971 in 70 county boroughs according to cause of death, sex, and age

\begin{tabular}{|c|c|c|c|c|c|c|c|c|}
\hline \multirow[b]{3}{*}{ Cause of death } & \multicolumn{4}{|l|}{$M A L E S$} & \multicolumn{4}{|c|}{$F E M A L E S$} \\
\hline & \multicolumn{2}{|l|}{$45-64$} & \multicolumn{2}{|l|}{$65-74$} & \multicolumn{2}{|l|}{$45-64$} & \multicolumn{2}{|l|}{$65-74$} \\
\hline & Smoke & $\mathrm{SO}_{2}$ & Smoke & $\mathrm{SO}_{2}$ & Smoke & $\mathrm{SO}_{2}$ & Smoke & $\mathrm{SO}_{2}$ \\
\hline $\begin{array}{l}\text { All causes } \\
\text { Malignant neoplasms }\end{array}$ & -0.06 & $0 \cdot 16^{*}$ & -0.07 & $0 \cdot 20^{* * *}$ & -0.03 & $0 \cdot 20^{* *}$ & -0.04 & $0 \cdot 26^{* * * *}$ \\
\hline $\begin{array}{l}\text { Malignant neoplasms } \\
\text { Stomach } \\
\text { Trachea, bronchus, and lung } \\
\text { Hypertensive disease } \\
\text { Ischaemic heart disease } \\
\text { Influenza } \\
\text { Pneumonia } \\
\text { Chronic bronchitis }\end{array}$ & $\begin{array}{r}-0.04 \\
-0.06 \\
-0.12 \\
-0.04 \\
-0.25 \\
0.14 \\
-0.10\end{array}$ & $\begin{array}{l}-0.06 \\
0.02 \\
0.56^{* * * *} \\
0.31^{* *} \\
0.28^{*} \\
-0.11 \\
0.16\end{array}$ & $\begin{array}{r}0.00 \\
-0.01 \\
-0.21 \\
0.05 \\
\mp \mathrm{N} \mathrm{A} \\
0.01 \\
-0.06\end{array}$ & $\begin{array}{r}-0.05 \\
0.00 \\
0.25 \\
0.28 \\
\text { N A } \\
0.08 \\
0.15\end{array}$ & $\begin{array}{r}0.04 \\
-0.10 \\
-0.18 \\
-0.07 \\
\mathrm{~N} A \\
0.05 \\
-0.07\end{array}$ & $\begin{array}{l}0 \cdot 12 \\
0 \cdot 16 \\
0 \cdot 53^{* * *} \\
0 \cdot 17 \\
\text { N A } \\
0 \cdot 11 \\
0 \cdot 26^{* *}\end{array}$ & $\begin{array}{r}-0.04 \\
0.04 \\
-0.02 \\
0.09 \\
\mathrm{~N} A \\
0.01 \\
-0.07\end{array}$ & $\begin{array}{r}-0.01 \\
0.15 \\
0.02 \\
0.06 \\
\text { N A } \\
0.19 \\
0.08\end{array}$ \\
\hline
\end{tabular}

+See footnote to Table 2 .

${ }^{*} \mathrm{p}<0.10 \quad{ }^{* *} \mathrm{p}<0.05 \mathrm{p}<0.01 \quad * * * \mathrm{p}<0.001 \quad \neq \mathrm{N} A=$ not analysed 
The results of the optimally weighted regressions of transformed mortality rates are shown in Table 2 for the 95 county and London boroughs, and in Table 3 for the 70 county boroughs alone. These regressions take into account all the confounding variables shown in Table 1 with the exception of water hardness and prevalence of smoking. No significant partial relation of smoke with any of the mortality rates was found in either data set. A significant positive relation $(p<0.05)$ was found between $\mathrm{SO}_{2}$ and hypertensive disease in males aged 45 to 64 , and with chronic bronchitis in females of the same age, in the 95 county and London boroughs. These associations were increased in the 70 county boroughs alone, and a number of other significant relations with $\mathrm{SO}_{2}$ levels were found, principally of mortality from all causes, and hypertensive disease in females aged 45 to $64(p<0 \cdot 01)$. Transformed mortality rates for influenza were not analysed, except for males aged 45 to 64 , because of zero death rates in a number of boroughs, but optimally weighted analyses of untransformed rates showed negative relations with smoke and $\mathrm{SO}_{2}$ which were significant $(p<0.05)$ for males aged 65 to 74 in the county boroughs and, for $\mathrm{SO}_{2}$ only, for females aged 65 to 74 in the county and London boroughs. Results for all-cause mortality in infants under the age of 1 showed no association with smoke or $\mathrm{SO}_{2}$. Pneumonia, analysed by regressions of untransformed rates, again because of some zero mortality rates, showed no significant relations with smoke or $\mathrm{SO}_{2}$.

The inclusion of the limited data on smoking prevalence in the analyses of mortality from all causes and chronic bronchitis in males weakened all the positive associations with $\mathrm{SO}_{2}$, as prevalence of male smoking was found to be positively correlated with $\mathrm{SO}_{2}$. The correlations were 0.40 for the county and London boroughs, and 0.50 for the county boroughs alone. The data on female smoking prevalence, however, were less strongly related to $\mathrm{SO}_{2}$ levels, $(\mathrm{r}=0.26$ and 0.34 respectively), and their inclusion had no effect on the significant relations found between all-cause mortality in females and $\mathrm{SO}_{2}$ in the county boroughs, and chronic bronchitis mortality in females aged 45 to 64 in either set of data.

In analyses in which water hardness was taken into account, missing values reduced the number of county and London boroughs to 88 , and county boroughs alone to 66 . The inclusion of water hardness in the analysis of hypertensive disease mortality had no effect on its relation with $\mathrm{SO}_{2}$, but the association of ischaemic heart disease mortality with $\mathrm{SO}_{2}$ in males for the county boroughs was reduced.

In the majority of cases the independent variables explained over $50 \%$ of the variation in the mortality rates. The percentage of the variation explained when that due to binomial sampling variation was added was in almost all cases over $70 \%$ and in the majority over $80 \%$. The exceptions were mainly in the analyses of hypertensive disease and pneumonia.

Table 4 shows the standardised regression coefficients obtained in the unweighted regressions of mortality rates for the 64 county boroughs for which Daly's index was available in addition to 1971 smoke and $\mathrm{SO}_{2}$ levels. The levels of significance found by Gardner ${ }^{8}{ }^{9}$ in his comparable analyses of mortality data centred around 1961 and 1951 are also given.

Table 4 Standardised regression coefficients for Daly's index from unweighted analysis in 64 county boroughs (1969-73) compared with those found by Gardner (1958-64, 1948-54)

\begin{tabular}{|c|c|c|c|c|c|c|c|}
\hline \multirow[b]{3}{*}{ Sex } & \multirow[b]{3}{*}{$\begin{array}{l}\text { Age group } \\
\text { (years) }\end{array}$} & \multirow[b]{3}{*}{$\begin{array}{l}\text { Period of } \\
\text { mortality } \\
\text { data }\end{array}$} & \multicolumn{5}{|c|}{ CAUSE OF DEATH } \\
\hline & & & \multirow[b]{2}{*}{ All causes } & \multicolumn{2}{|c|}{ Malignant neoplasms } & \multirow[b]{2}{*}{$\begin{array}{l}\text { Cardiovascular } \\
\text { disease }\end{array}$} & \multirow[b]{2}{*}{$\begin{array}{l}\text { Chronic } \\
\text { bronchitis }\end{array}$} \\
\hline & & & & Stomach & $\begin{array}{l}\text { Trachea, } \\
\text { bronchus, } \\
\text { and lung }\end{array}$ & & \\
\hline \multirow[t]{2}{*}{ Males } & $45-64$ & $\begin{array}{l}1969-73 \\
1958-64 \\
1948-54\end{array}$ & $\begin{array}{l}0 \cdot 26^{*} \\
0 \cdot 36^{* * *} \\
0 \cdot 48^{* * * *}\end{array}$ & $\begin{array}{l}0.42 \\
0.40^{* * *} \\
0.40^{* *}\end{array}$ & $\begin{array}{l}0.07 \\
0.53^{* * *} \\
0.71^{* * * *}\end{array}$ & $\begin{array}{l}0.11 \\
0.28^{* *} \\
0.25^{* *}\end{array}$ & $\begin{array}{l}0.02 \\
0.32^{* *} \\
0.48^{* * * * *}\end{array}$ \\
\hline & $65-74$ & $\begin{array}{l}1969-73 \\
1958-64 \\
1950-54\end{array}$ & $\begin{array}{l}0.13 \\
0.17 \\
0.28^{* *}\end{array}$ & $\begin{array}{l}0.25 \\
0.37^{* *} \\
0.06\end{array}$ & $\begin{array}{l}0 \cdot 15 \\
0 \cdot 68^{* * * *} \\
0 \cdot 87^{* * * *}\end{array}$ & $\begin{array}{l}-0.08 \\
-0.04 \\
-0.01\end{array}$ & $\begin{array}{l}-0.06 \\
0.31 \\
0.37^{* *}\end{array}$ \\
\hline \multirow[t]{2}{*}{ Females } & $45-64$ & $\begin{array}{l}1969-73 \\
1958-64 \\
1948-54\end{array}$ & $\begin{array}{l}0 \cdot 30^{*} \\
0 \cdot 12 \\
0 \cdot 20\end{array}$ & $\begin{array}{c}0.63^{* *} \\
-0.03 \\
0.11\end{array}$ & $\begin{array}{l}-0.02 \\
-0.64^{* * *} \\
0.49^{* *}\end{array}$ & $\begin{array}{l}0.07 \\
0.10 \\
0.09\end{array}$ & $\begin{array}{l}-0.02 \\
0.33^{* *} \\
0.49 * * *\end{array}$ \\
\hline & $65-74$ & $\begin{array}{l}1969-73 \\
1958-64 \\
1950-54\end{array}$ & $\begin{array}{r}0.10 \\
-0.05 \\
0.02\end{array}$ & $\begin{array}{r}0.10 \\
0.16 \\
-0.04\end{array}$ & $\begin{array}{l}0.07 \\
0.25 \\
0.61^{* * *}\end{array}$ & $\begin{array}{r}0.23 \\
-0.22 \\
-0.08\end{array}$ & $\begin{array}{l}0.03 \\
0.40^{*} \\
0.31\end{array}$ \\
\hline
\end{tabular}


Although allowance must be made for some differences between Gardner's set of boroughs and the 64 in our analysis, and between the sets of socioeconomic variables, the contrast in the results is striking. We found only one significant association, for mortality due to malignant neoplasms of the stomach, whereas Gardner found significant associations in almost all cases for malignant neoplasms of the trachea, bronchus and lung, and for chronic bronchitis. The percentage of variation explained by our method was higher for these two causes of death in each case than that explained by Gardner's model for either the 1961 or 1951 analysis.

\section{Discussion}

The results for both the 95 county and London boroughs combined and the 70 county boroughs alone showed no significant relation between smoke levels and mortality from any cause. This finding was unexpected in view of the results of earlier studies. ${ }^{68}$ However, it was supported by the analyses using Daly's index, which showed no relation to mortality in our analyses but which in the past had shown highly significant relations to respiratory causes of death. Daly's index is not a direct measure of smoke but, even 20 years after the measurements on which it was based were made, the correlation between it and 1971 smoke levels was surprisingly high $(r=0.52)$. Our results thus show clearly that neither smoke as measured in the year of death nor as estimated in the past was related to mortality rates after allowing for other factors.

There were, however, several significant results for $\mathrm{SO}_{2}$. Although they may reflect a real effect, a causal role for $\mathrm{SO}_{2}$ in mortality independent of an effect of smoke seems unlikely, since there is no reasonable mechanism by which $\mathrm{SO}_{2}$ alone in the concentrations found in the ambient air in 1971 could either cause death preferentially in women, as we observed, or even cause death at all. Thus the few significant results we obtained seem more likely to be due to chance and to factors omitted from the model than to any causal effect of $\mathrm{SO}_{2}$.

The analyses which we used to compare our results with those of Gardner tend to support this view. The relation between pollution levels and mortality from chronic bronchitis was found to have changed substantially over the years to the extent that inverse (albeit not statistically significant) relations with Daly's index were found in 1971, contrary to earlier observations. The same reversal of trend over the years was also found for mortality from malignant neoplasms of the trachea, bronchus and lung.

These results indicate that neither contemporaneous levels of smoke and $\mathrm{SO}_{2}$ nor a measure of pollution made 20 years earlier were related to respiratory disease mortality in 1969-73 in any systematic way. When considered in conjunction with Daly's and Gardner's findings, they suggest a declining effect of pollution on mortality as pollution levels have fallen since the mid-1950s.

Studies of the chronic effects of air pollution on mortality have been valuable in the past in that they contributed to the evidence that the levels of air pollution were not sufficiently low for good health. However, they suffered from many drawbacks because of the nature of the data. In some of the studies many confounding variables were included but the influence of cigarette smoking, occupational exposure, and other noxious pollutants was never effectively taken into account, principally because of the lack of suitable data. The objection to the positive findings of earlier studies was that the significant associations may have been due to the omission of important confounding variables. In our study, where we found no real evidence of an association even without the extra confounding variables, we asked whether the inclusion of these variables would have increased the significance of the pollution variables. In other words, what alternative explanations may there be for our negative findings?

We have attempted to take tobacco smoking into account in a secondary analysis using General Household Survey data for nine regions. Where there was an association between mortality and smoking the effect of the latter was to reduce the significance of $\mathrm{SO}_{2}$.

It was our intention to refer to occupational data if we found any unusual deviation of observed mortality from the model because such data might have provided insight into the reasons for the deviation. As no such deviation was found they were not included.

Other pollutants were undoubtedly present in the air. For these to have removed the effects of $\mathrm{SO}_{2}$ and smoke from the model, one would have had to postulate that they occurred at higher levels in the boroughs with lower levels of smoke and $\mathrm{SO}_{2}$ and that they caused death. The tendency for industrial pollutants to occur in the same places as higher levels of smoke and sulphur dioxide makes this unlikely.

A more probable explanation might be that between 1961 and 1971 there was considerable migration from inner city areas due to redevelopment and an increase in the mobility of the population. The most polluted areas would tend to have the worst housing. Redevelopment of these areas with removal of the population to outside the borough boundaries could have reduced the mortality ascribed to the borough, thereby weakening the link between mortality and pollution levels. 
Finally, our model may be insufficient or our data too unreliable. The inaccuracies of both mortality and air pollution data are substantial but they should have been equally substantial for earlier analyses which showed significant effects of pollution. Moreover, the model described in this report fits the data in most cases extremely well, accounting for over $80 \%$ of the variation in mortality from chronic bronchitis and malignant neoplasms of the trachea, bronchus and lung, so we believe that neither unreliable data nor a poor model can explain our negative results.

Several recent American studies ${ }^{16-18}$ have reported positive associations between mortality and various air pollutants but they have suffered from a number of methodological problems. We have tried to avoid some of these problems by using age- and sex-specific death rates, a range of confounding variables including cigarette smoking, relatively small well-populated areas generously served with pollution monitors taking daily samples, and by weighting the regressions to take into account the size of the population units.

We have shown that with these refinements, or as a result of the decline in levels of smoke and $\mathrm{SO}_{2}$ or of environmental, social, or population changes for which we have no information, analysis of group data can no longer provide evidence of an association between mortality in England and Wales and atmospheric pollution from smoke and sulphur dioxide.

We thank Dr. D. Nicol of the Department of the Environment, Dr. Adelstein and his colleagues at the Office of Population Censuses and Surveys, Dr. Keddie and his colleagues at the Warren Spring Laboratory, and Mr. Lacey and his colleagues at the Water Research Centre. We also thank Dr. Pocock, Mr. Clyde, and the department secretaries. The work was carried out under contract to the Department of the Environment and the Department of Health and Social Security.

Reprints from Ms. S. Chinn, Senior Lecturer in Medical Statistics, Department of Community Medicine, St. Thomas's Hospital Medical School, London SE1 7EH.

\section{References}

${ }^{1}$ Ashley DJB. The distribution of lung cancer and bronchitis in England and Wales. Br J Cancer 1967; 21: 243-59.

${ }^{2}$ Buck SF, Brown DA. Mortality from lung cancer and bronchitis in relation to smoke and sulphur dioxide concentration, population density and social index. Research paper No. 7. London: Tobacco Research Council, 1964.

${ }^{3}$ Fairbairn AS, Reid DD. Air pollution and other local factors in respiratory disease. Br J Prev Soc Med 1958; 12: 94-103.

4 Gorham E. Bronchitis and the acidity of urban populations. Lancet 1958; ii: 691.

${ }^{5}$ Pemberton J, Goldberg C. Air pollution and bronchitis. $\mathrm{Br}$ Med J 1954; ii: 567-70.

${ }^{6} \mathrm{Daly} \mathrm{C}$. Air pollution and causes of death. Br J Prev Soc Med 1959; 13: 14-27.

${ }^{7}$ Stocks P. Cancer and bronchitis mortality in relation to atmospheric deposit and smoke. Br Med J 1959; i: 74-9.

${ }^{8}$ Gardner MJ, Crawford MD, Morris JN. Patterns of mortality in middle and early old age in the county boroughs of England and Wales. Br J Prev Soc Med 1969; 23: 133-40.

${ }^{\circ}$ Gardner MJ. Using the environment to explain and predict mortality. J $R$ Stat Soc $A$ 1973; 136: 421-40.

${ }^{10}$ Collins JJ, Kasap HS, Holland WW. Environmental factors in child mortality in England and Wales. Am J Epidemiol 1971; 93: 10-22.

${ }^{11}$ Lave LB, Seskin EP. An analysis of the association between U S mortality and air pollution.J Am Stat Assoc 1973; 68: 284-90.

12 Warren Spring Laboratory. The National Survey of Smoke and Sulphur Dioxide-Quality control and the air sampling arrangements. LR 308 (AP). Stevenage: Warren Spring Laboratory, 1979.

${ }^{13}$ Holland WW, Spicer CC, Wilson JMG. Influence of the weather on respiratory and heart disease. Lancet 1961; ii: $338-41$.

${ }^{14}$ Dudley EF, Beldin RA, Johnson BC. Climate, water hardness and coronary heart disease. J Chronic Dis 1969; 22: 25-48.

${ }^{15}$ Cox DR. Analysis of binary data. (Section 3.1), London: Methuen, 1970.

${ }^{16}$ Lave LB, Seskin EP. Air pollution and human health. Baltimore: Johns Hopkins University Press, 1977.

${ }^{17}$ Crocker TD, Schulze W, Ben-David S, Kneese AV. Methods development for assessing air pollution control benefits. Vol. I: Experiments in the economics of air pollution. EPA-600/5-79-001a. Research Triangle Park, North Carolina: Environmental Protection Agency, 1979.

${ }^{18} \mathrm{Lipfert} \mathrm{FW}$. The association of air pollution with human mortality: Multiple regression results for $136 \mathrm{U}$ S cities, 1969. Paper presented at the 70th annual meeting of the Air Pollution Control Association, June 1977. Toronto, Canada. 